\title{
Preparação, caracterização e aplicação antimicrobiana de nanopartículas de prata estabilizadas em extrato de girassol (Heliantus Annus)
}

\author{
Development, characterization and application of silver nanoparticles stabilized with sunflower \\ (Helianthus annuus) extract
}

Preparación, caracterización y aplicación antimicrobiana de nanopartículos de plata estabilizados en extracto de girasol (heliantus annus)

Recebido: 27/04/2021 | Revisado: 05/05/2021 | Aceito: 07/05/2021 | Publicado: 30/05/2021

Taciany Alves Batista Lemos

ORCID: https://orcid.org/0000-0002-8110-958 Centro Universitário UNIFACID/WYDEN, Brasil

E-mail: tacianyablemos@hotmail.com

Deuzuita dos Santos Freitas Viana

ORCID: https://orcid.org/0000-0002-1902-6505 Centro Universitário UNIFACID/WYDEN, Brasil

E-mail: deuzuitasfv@gmail.com

Vicente Galber Freitas Viana

ORCID: https://orcid.org/ 0000-0002-3863-6974 Universidade Federal do Piaú, Brasil E-mail: galber@ifpi.edu.br

Matheus Henrique da Silva Lemos

ORCID: https://orcid.org/0000-0002-3554-0141 Universidade Federal do Piauí, Brasil E-mail: lemosmhs@gmail.com

Girlene Soares de Figueirêdo

ORCID: https://orcid.org/0000-0002-6710-1549 Universidade Federal do Piauí, Brasil E-mail: girlenesf@gmail.com

\begin{abstract}
Resumo
Este estudo objetivou analisar o efeito do extrato de Helianthus Annuus (AgNP@Ha) na síntese de uma nanopartícula de prata e avaliar sua ação antimicrobiana contra bactérias gram-positivo, gram-negativo e fungos. A produção da nanopartícula foi realizada em agitação sobre uma chapa magnética aquecida até a configuração total da nano, ao final foi utilizado o extrato para a estabilização da mesma, o seu tamanho comprovado através do UV-VIS. A análise microbiológica foi feita em placa com medição do tamanho do halo inibitório formado. Obteve-se uma AgNP@Ha com diâmetros de partículas coloidais com variação de 422 - $414 \mathrm{~nm}(\lambda \max 422 \mathrm{~nm})$ com efeito de formação de halo sobre as linhagens de S. aureus $(16 \mathrm{~mm})$, E. coli $(12 \mathrm{~mm})$ e $P$. aeruginosa $(10 \mathrm{~mm})$, enquanto as AgNPs que não foram estabilizadas com o girassol não apresentaram o halo inibitório. Através desta pesquisa foi possível comprovar a melhoria da eficiência de ação e de produção ao se utilizar o extrato de girassol para a estabilização. A síntese de nanopartículas de prata utilizando o extrato das sementes de Helianhtus annuus promoveu uma abordagem mais amigável ao meio ambiente, simples, eficiente e com baixo custo para a obtenção de nanopartículas se tornando um excelente produto com potencial antimicrobiano para ser comercializado além de servir como subsídio para pesquisas posteriores.
\end{abstract}

Palavras-chave: Nanopartículas de prata; Antimicrobiana; Heliantus annus.

\begin{abstract}
The use of nanoparticles has been applied in several areas of pharmacology, due to its advantages before absorption, distribution and its effect on disease, especially when it is compose of natural products due to its ability to reduce possible toxic effects of the final product. The study aimed to analyze the effect of Helianthus Annuus extract (AgNP@Ha) in the synthesis of a silver nanoparticle and to evaluate its antimicrobial action against gram-positive, gram-negative bacteria and fungi. The production of the nanoparticle was carried out by stirring over a heated magnetic plate until the complete configuration of the nanoparticle was formed, then, the extract was used to stabilize the nanoparticle, its size was verified by means of UV-VIS. Microbiological analysis was performed on a plate, measuring the size of the inhibitory halo formed. An AgNP@Ha $414 \mathrm{~nm}$ that were stabilized using sunflower was obtained with halo formation effect on S. aureus $(16 \mathrm{~mm})$, E. coli $(12 \mathrm{~mm})$ and P. aeruginosa $(10 \mathrm{~mm})$ strains, while AgNPs that were not stabilized with sunflower did not show the inhibitory halo. Through this research it was possible
\end{abstract}


to prove the improvement of pharmacological effect and production efficiency of silver nanoparticles when using sunflower seed extract as a stabilizer The synthesis of silver nanoparticles using the extract of Helianhtus annuus seeds promoted a more environmentally friendly, simple, efficient and low cost approach to obtain nanoparticles, becoming an excellent product with antimicrobial potential to be marketed in addition to serving as a subsidy for further research.

Keywords: Nanoparticles silver; Antimicrobial; Helianthus annuus.

\section{Resumen}

El uso de nanopartículas se ha aplicado en diversas áreas de la farmacología, debido a sus ventajas en cuanto a absorción, distribución y sus efectos frente a enfermedades, especialmente cuando existen productos de origen natural en su composición, ya que tienen la capacidad para reducir posibles efectos tóxicos. que el producto final. El estudio tuvo como objetivo analizar el efecto del extracto de Helianthus Annuus (AgNP @ Ha) en la síntesis de una nanopartícula de plata y evaluar su acción antimicrobiana frente a bacterias y hongos grampositivos, gramnegativos y hongos. La producción de la nanopartícula se realizó en agitación sobre una placa magnética calentada hasta la configuración total de la nano, al final se utilizó el extracto para estabilizarla, su tamaño confirmado por UV-VIS. El análisis microbiológico se realizó en una placa midiendo el tamaño del halo inhibidor formado. Se obtuvo un AgNP @ Ha con diámetros de partículas coloidales que van desde 422 - $414 \mathrm{~nm}$ ( $\lambda \max 422 \mathrm{~nm}$ ) con un efecto de halo en las cepas de S. aureus $(16 \mathrm{~mm})$, E. coli $(12 \mathrm{~mm})$ y P. aeruginosa $(10 \mathrm{~mm})$, mientras que los AgNP que no se estabilizaron con girasol no presentaron el halo inhibidor. A través de esta investigación se pudo comprobar la mejora en la eficiencia de acción y producción al utilizar extracto de girasol para la estabilización. La síntesis de nanopartículas de plata utilizando el extracto de semillas de Helianhtus annuus promovió un enfoque más amigable con el medio ambiente, simple, eficiente y de bajo costo para la obtención de nanopartículas, convirtiéndose en un excelente producto con potencial antimicrobiano para ser comercializado además de servir como un subsidio para futuras investigaciones.

Palabras clave: Nanopartículas de plata; Antimicrobiano; Heliantus annus.

\section{Introdução}

A nanotecnologia desenvolveu-se rapidamente durante a última década e com aplicações diversas e estratégicas, em especial nas áreas de saúde, energia e eletrônica, com objetivo de manipular moléculas, átomos e demais partículas de grandeza manométrica para a criação de novos materiais e propriedades. Apresenta um campo de atuação multidisciplinar, em destaque tem-se o desenvolvimento e utilização das nanopartículas (NPs), principalmente pela sua maleabilidade na aplicação que pode variar da indústria alimentícia até a cosmética (Nogueira et al., 2013; Brinch et al., 2016).

As nanopartículas são moléculas com dimensões extremamente pequenas da ordem de dezenas de nanômetros, em geral apresenta diâmetro entre 1 a $100 \mathrm{~nm}$, contudo tem uma grande área superficial para contato e exibem propriedades mecânicas, óticas, magnéticas e químicas distintas das partículas e superfícies macroscópicas. Sua matéria prima pode ser bem variada, indo de compostos naturais até a sintéticos, mas em geral são classificadas em quatro classes: fulerenos, metais, cerâmica e polímeros (Simonet; Valcárcel, 2009; Lucky; Soo; Zhang, 2015; Khan; Saeed; Khan, 2017).

A síntese verde está ganhando espaço na pesquisa e desenvolvimento da atualidade, sua utilização reduz a produção de resíduos indesejáveis, consequentemente evita a poluição, e também incentiva na utilização dos recursos naturais. Para a síntese de nanopartículas de prata tem-se considerado o uso da biodiversidade vegetal devido à disponibilidade de fitoquímicos existentes em vários extratos vegetais como exemplo tem-se o girassol (Sing, et al. 2018).

Diante o crescimento no número casos de infecções ocasionadas por cepas bacterianas em consequência da alta resistência aos fármacos e as poucas opções terapêuticas disponíveis, tem-se incentivado a busca de estratégias de pesquisa e o desenvolvimento de novos agentes antimicrobianos, o que inclui o descobrimento de novos compostos que tenham mecanismos de ação inovadores (Swietnicki, 2018).

Dentro deste contexto, os produtos naturais oriundos de plantas com atividades biológicas têm sido investigados como potenciais novos meios de tratamento e contenção das doenças infecciosas (Pinto et al., 2013). Ao longo dos anos, estudos que envolvem a ação antimicrobiana de fitoterápicos, em especial os óleos extraídos de algumas plantas, como o Girassol (Hellianthus annuus) que é cultivado comercialmente no mundo todo (Qiao et al., 2021). 
Este estudo possui relevância social e acadêmica, visto que nas últimas décadas, tem sido observado um grande interesse pelo potencial terapêutico das plantas medicinais. Dentro desta perspectiva um amplo número de plantas e seus compostos, tem se destacado para tratamentos e recebido grande atenção por apresentarem propriedades que os fazem atuar sobre sistemas biológicos provocando efeitos específicos.

Assim este trabalho ao ser realizado teve grande relevância para o meio cientifico na aplicabilidade desse novo material obtido a partir de um produto natural, o Helianthus annuus. Além disso, esta pesquisa faz uso de materiais amigável ao meio ambiente, simples, eficiente e com baixo custo para a obtenção de nanopartículas se tornando um excelente produto com potencial antimicrobiano para ser comercializado. Este trabalho teve como objetivo geral: Avaliar o potencial das nanopartículas de prata estabilizadas em Helianthus annuus (AgNP-Ha) com o intuito de investigar sua atividade antimicrobiana frente às espécies bacterianas Staphylococcus aureus, Pseudomonas aeruginosa, Escherichia coli, além da espécie fúngica Candida albicans. E como objetivos específicos: Sintetizar e caracterizar nanopartículas de prata estabilizadas em em Helianthus annuus (AgNP-Ha); caracterizar através de espectroscopia UV-VIS o comportamento óptico e morfológico de estruturas das nanopartículas de prata tanto em Helianthus annuus (AgNP-Ha).

\section{Metodologia}

Trata-se de uma pesquisa Experimental de abordagem descritiva laboratorial. De acordo com Gil (2012), a pesquisa experimental constitui o delineamento mais prestigiado nos meios científicos, que determina um objeto de estudo selecionando variáveis capazes de definir formas de controle e observar efeitos que as variáveis relacionadas ao objeto de estudo, fazendo com que o pesquisador se torne um agente ativo e não um observador passivo para assim, atingir os resultados esperados. O pesquisador deve fazer uso de aparelhos e instrumentos com técnicas modernas para alcançar as variáveis de causa e efeito obtidas no objeto de estudo. O pesquisador precisa manipular pelo menos um dos fatores que se acredita ser responsável pela ocorrência do fenômeno que está sendo pesquisado.

O trabalho foi desenvolvido no laboratório da UniFacid em parceria com o laboratório de química pertencente ao Instituto Federal do Piauí (IFPI). Realizada entre os meses de março e abril de 2020 inicialmente e finalizada no ano de 2021. Destaca-se que para coleta foi respeitada as recomendações da Organização Mundial de Saúde (OMS), relacionada a distanciamento social, referente à pandemia do Covid-19. As amostras de lâmina microbianas foram analisadas no mês de março de 2021, no laboratório de microbiologia da UFPI (Universidade Federal do Piauí), obedecendo aos protocolos de segurança estabelecidos.

A pesquisa não precisou ser submetida ao CEUA (Comitê de Ética em Uso de Animais) da UNIFACID, nem ao CEP (Comitê de Ética em Pesquisa), antes de iniciar a coleta de dados e desenvolvimento da pesquisa, por não se tratar de uma pesquisa com seres humanos nem animais. Respeitando assim os procedimentos éticos exigidos no trabalho.

\subsection{Produção do extrato de sementes de girassol}

Para realização desta etapa de produção do extrato foi comprado um envelope com $800 \mathrm{mg}$ de sementes de girassol Helianthus annuus- Isla, LOTE 003000919, com época de semeadura de aproximadamente seis meses possuindo ciclo (dias) de 60 verões e com um número aproximado de sementes de $20 \mathrm{~g}$. Posteriormente foram pesados $10 \mathrm{~g}$ de sementes de girassol macerado e incorporados em $100 \mathrm{~mL}$ de água destilada e mantidas em repouso por 24 horas. Após esse período foi realizado uma rota-evaporação para a obtenção do extrato concentrado que foram distribuídos e envasado em frascos vidro âmbar para impedir a perda de qualquer componente fotossensível até o momento do seu uso na estabilização das nanopartículas de prata durante o processo da sua produção. 
Figura 1- Sequencia experimental que mostra a produção do extrato de sementes de girassol.
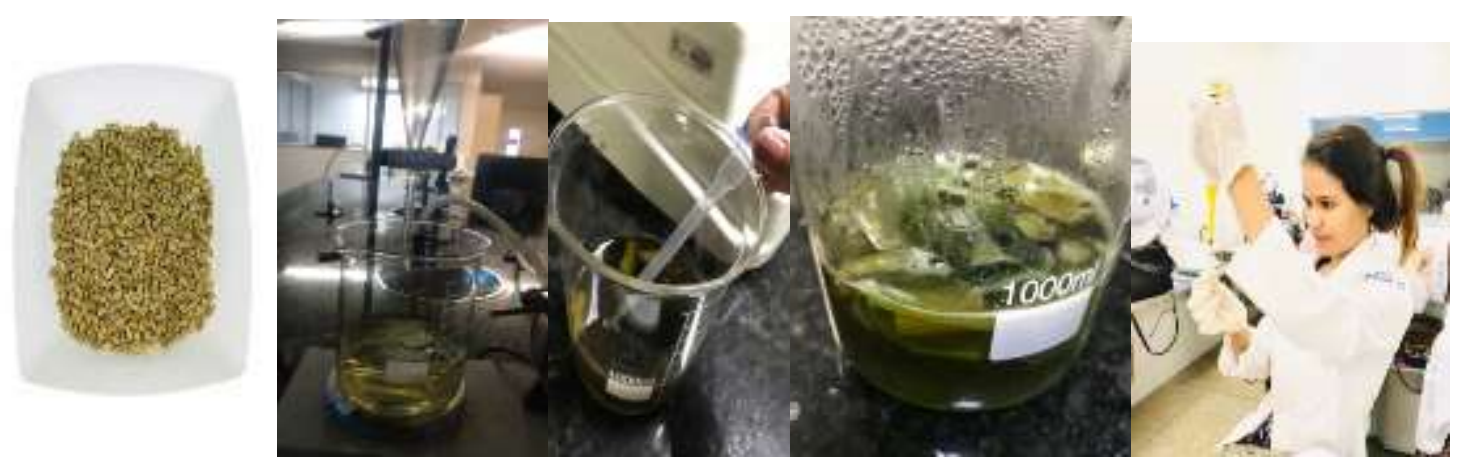

Fonte: Arquivo de Dispositivo Móvel (Autores).

$\mathrm{Na}$ sequência de fotos acima, que foi realizada entre os meses de março e abril de 2020, o laboratório de química pertencente ao Instituto Federal do Piauí (IFPI), podemos observar os grãos de extrato de girassol (Helianthus annuus) que foram pesados, macerados e incorporados em $100 \mathrm{~mL}$ de água destilada e mantidas em repouso posteriormente, na forma de suspensão aquosa, apresentando assim baixo impacto ambiental.

\subsection{Síntese de nanopartículas de prata estabilizadas em Helianthus annuus (AgNP-Ha)}

Sobre agitação magnética numa chapa aquecedora, uma solução de $125 \mathrm{~mL}$ de $\operatorname{AgNO}_{3}(1,0 \mathrm{mmol} / \mathrm{L})$ foi aquecida até ntrar em ebulição. Atingida a temperatura de ebulição, 5,0 mL de uma solução de citrato de sódio $1 \%$ foi gotejada na solução de $\mathrm{AgNO}_{3}$. O gotejamento ocorreu numa taxa de 1,0 gota por segundo. A mistura mantida sobre aquecimento e agitação foi mudando de cor até atingir uma coloração amarelo acastanhado. Essa coloração indica a redução da prata de $\mathrm{Ag}^{+}$para $\mathrm{Ag}$ com formação das nanopartículas. Após atingir essa coloração, foi desligado o aquecimento da chapa aquecedora, no entanto, a solução foi mantida sobre agitação magnética. Após a solução contendo as nanopartículas atingir a temperara ambiente $\left(25{ }^{0} \mathrm{C}\right)$ foi adicionado a mistura, o extrato das sementes de girassol previamente produzida. Após 15 minutos, a solução de $\mathrm{AgNO}_{3} /$ citrato/girassol foi armazenada num frasco âmbar.

Deve-se ressaltar que nas reações realizadas houve variação na coloração o que é um bom um bom indício da formação de nanopartículas de prata é a forte coloração amarelo/ambar na amostra, instantes após a etapa de adição do agente estabilizador, conforme podemos observar na Figura 2.

Figura 2- Sequência da formação química e aspecto visual da solução de nanopartícula de prata estabilizadas em Helianthus annuus (AgNP-Ha)
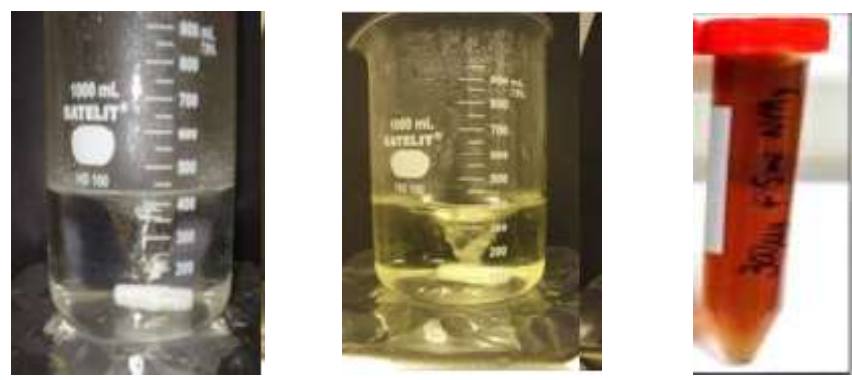

Fonte: Arquivo de Dispositivo Móvel (Autores).

A cor amarela característica observada na prata coloidal é resultado da absorção da radiação eletromagnética. Com a elevação das partículas de prata, a cor amarela característica da solução padrão passa para laranja e, posteriormente, alaranjada 
até atingir a coloração característica da prata em escala macroscópica (marron acastanhada). Esse fenômeno de diferença de coloração pode ser explicado pela adição de solução de nitrato de prata, que faz com que as partículas se aglomerem e se tornem maiores. (Junior et al., 2013).

As nanopartículas obtidas através da redução por extratos de plantas são na sua maioria esféricas, mas através de outros agentes químicos podem apresentar formatos variados como cubos, triângulos, bastões e até dendritos (Khodashenas et al., 2015).

\subsection{Caracterização e confirmação das nanopartículas}

A confirmação da síntese da nanopartícula foi realizada pele método de espectroscopia de luz ultravioleta visível (UV-Vis), os espectros foram obtidos em um espectrofotômetro modelo UV-6100S da Allcrom com feixe duplo. Os parâmetros de analises serão: faixa de varredura de 1900-900nm, abertura de fenda = 2,0 nm e resolução espectral de 1,0 nm. Foram utilizados cubetas de quartzo com caminho óptico de 1,0 cm e as amostras foram dispersas em água com o auxílio de banho ultrassônico.

\subsection{Linhagens microbianas}

Os testes de verificação de atividade antimicrobiana da AgNP-Ha foram realizados contra cepas microbiano padrão. Sendo uma espécie bacteriana gram-positiva, Staphylococcus aureus ATCC 25923, uma espécie gram-negativa, Escherichia coli ATCC 25922, e uma espécie de fungo leveduriforme, Candida albicans ATCC 10231. Além das cepas padrão, também se determinou a atividade antimicrobina do referido composto contra uma cepa de Pseudomonas aeruginosa ATCC 27583, isolada de água de tratamento hospitalar.

As cepas bacterianas foram mantidas em tubos contendo ágar Brain Infusion Heart (BHI, Himedia, Índia) inclinados a $4{ }^{\circ} \mathrm{C}$, e antes do ensaio as células foram cultivadas durante uma noite a $37^{\circ} \mathrm{C}$ em Brain Heart Infusion (BHI, Himedia, Índia). O ágar Sabouraud Dextrose foi usado tanto para manutenção da cepa de levedura como para o cultivo das células.

\subsection{Preparo do inóculo microbiano}

O inóculo das espécies microbianas que foram testadas foi padronizado pelo método de suspensão direta das colônias CLSI (2009) em solução salina esterilizada. Todas as culturas semeadas foram incubadas à temperatura de $37^{\circ} \mathrm{C}$ em estufa de crescimento. Por meio de uma alça de platina esterilizada realizou-se a inoculação dos micro-organismos repicados, em tubos de ensaio com $1 \mathrm{ml}$ de soro fisiológico a $0,9 \%$. A suspensão de células foi ajustada a concentração de $1 \times 10^{8} \mathrm{UFC} / \mathrm{mL}$, que corresponde a solução padrão de McFarland de 0,5.

\subsection{Teste de suscetibilidade por meio de disco difusão em meio sólido}

Para a determinação da atividade antimicrobiana das substâncias frente às cepas microbianas, utilizou-se o método preconizado por Bauer e colaboradores (1966) com adaptações. O ensaio consiste na aplicação do inóculo utilizando um swab esterilizado em toda a superfície de uma placa de Petri de $45 \mathrm{~mm}$ com meio ágar Muller Hinton. Posteriormente, foram adicionados discos contendo AgNP-Ha na concentração de 1,0 mmol/L.

Em seguida, as placas foram incubadas por um período de 24 horas em estufa de crescimento bacteriológico, em temperatura de $37^{\circ} \mathrm{C}$. Cada experimento foi realizado em triplicata. Após o período de incubação, se houvesse a formação de halos de inibição do crescimento microbiano ao redor de cada disco, estes foram mensurados com auxílio de um paquímetro em milímetros. 


\section{Resultados e Discussão}

\subsection{Caracterização Visual}

Estudos sugerem que quando há presença de nanopartículas de prata na solução formada, a solução se torna mais escura, indo de transparente para um amarelo acastanhado, na sequência da figura 2 mostram fotografias das amostras contendo nanopartículas de prata produzidas na presença do extrato de girassol concentrações de citrato de prata e com diferentes tempos de reação.

\subsection{Espectroscopia síntese e caracterização das nanopartículas}

A caracterização das AgNPs foi feita através de espectroscopia UV-VIS obtiveram resultados promissores e inéditos, uma vez que não há na literatura nenhum relato sobre a identificação de proteínas na sintase e/ou na estabilização em Helianthus annuus para aplicações bactericidas. Na Figura 3 traz a faixa padrão de cada uma das substâncias utilizadas para a síntese e estabilização das nanopartículas, tanto o extrato de girassol quanto a solução de citrato de sódio $1 \%$ não apresentam qualquer processo de absorção de luz na região visível, enquanto a absorção de luz para a solução de nitrato de prata é muito pequena, podendo também ser desconsiderada e consequentemente ser citadas como soluções incolores.

Essa caracterização inicial da solução de produção como incolor se dá pelo princípio da qual as partículas de pratas são produzidas, pois nesse processo de redução para prata, em que ao ocorrer a transformação do nitrato de prata para as nanopartículas de prata ocorre uma mudança de coloração, em geral para um marrom escuro, que será detectada e quantificada de acordo com a quantidade produzida na síntese (Ravindra et al., 2010; Al-Shabib et al., 2020).

Figura 3: Gráfico UV-Vis das substâncias usadas na produção e estabilização das AgNPs.

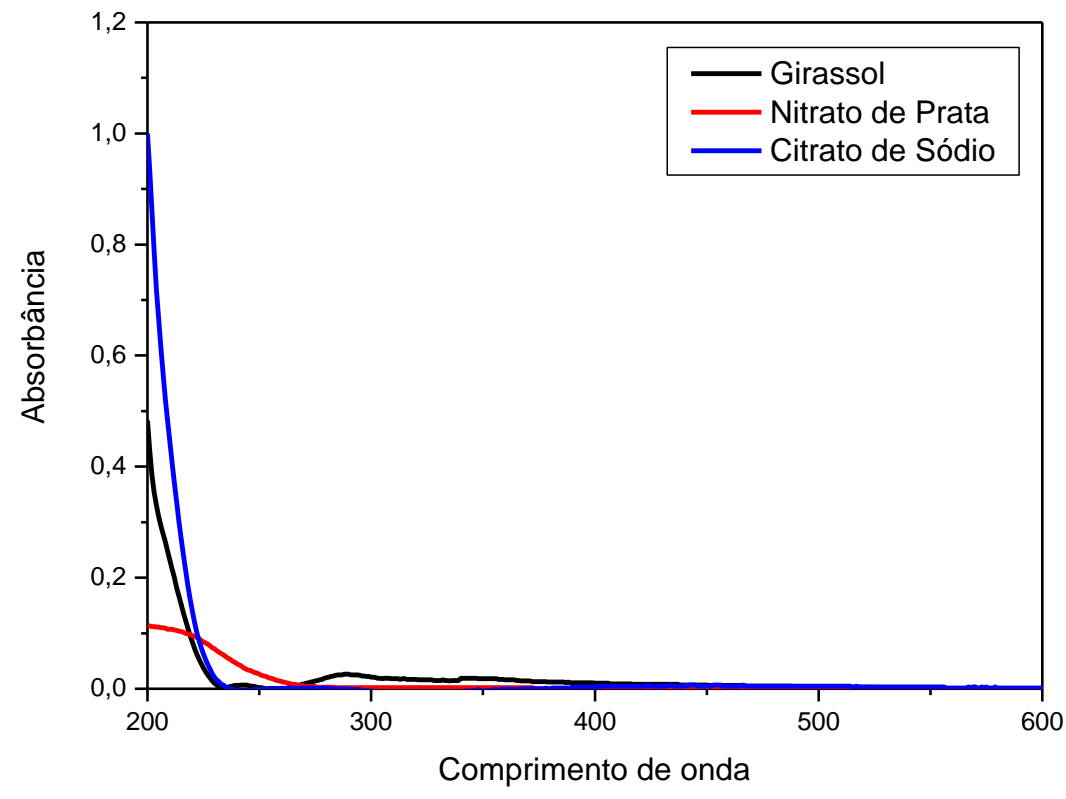

Fonte: Autores.

O segundo resultado obtido na caracterização foi os picos de UV-Vis derivados na nanopartícula na presença de citrato de sódio $1 \%$ e na estabilização com o extrato de sementes de girassol, representado pela Figura 5.1. Como observado as bandas de absorção de luz com comprimento de onda máximo próximo a $400 \mathrm{~nm}$, indicam que as nanopartículas de pratas (AgNPs) foram produzidas, ressaltado que quanto menor o comprimento de onda máximo, menor o tamanho das nanopartículas produzidas, o contrário também é verdadeiro. 
Ao comparar as nanopartículas formadas na presença do citrato de sódio com ou sem a adição do extrato de girassol, percebemos que há uma redução do pico máximo de comprimento de onda, indo de 422 para 414 nm, o que por consequência nos leva a deduzir que ao ser adicionado o extrato de girassol a síntese produz nanopartículas menores, essa otimização das nanopartículas, facilita a toxicidade do material, já que quanto menor a nanopartícula mais facilidade a mesma tem de adentrar no nível celular e com isso ter atividade (Kim et al., 2012), assim como há a influência do tamanho da nanopartícula sobre a atividade antimicrobiana da substancia (Qasim et al., 2018).

Figura 3.1: Gráfico UV-Vis das AgNPs produzidas na presença do citrato de sódio $1 \%$ e estabilizada com o extrato de girassol

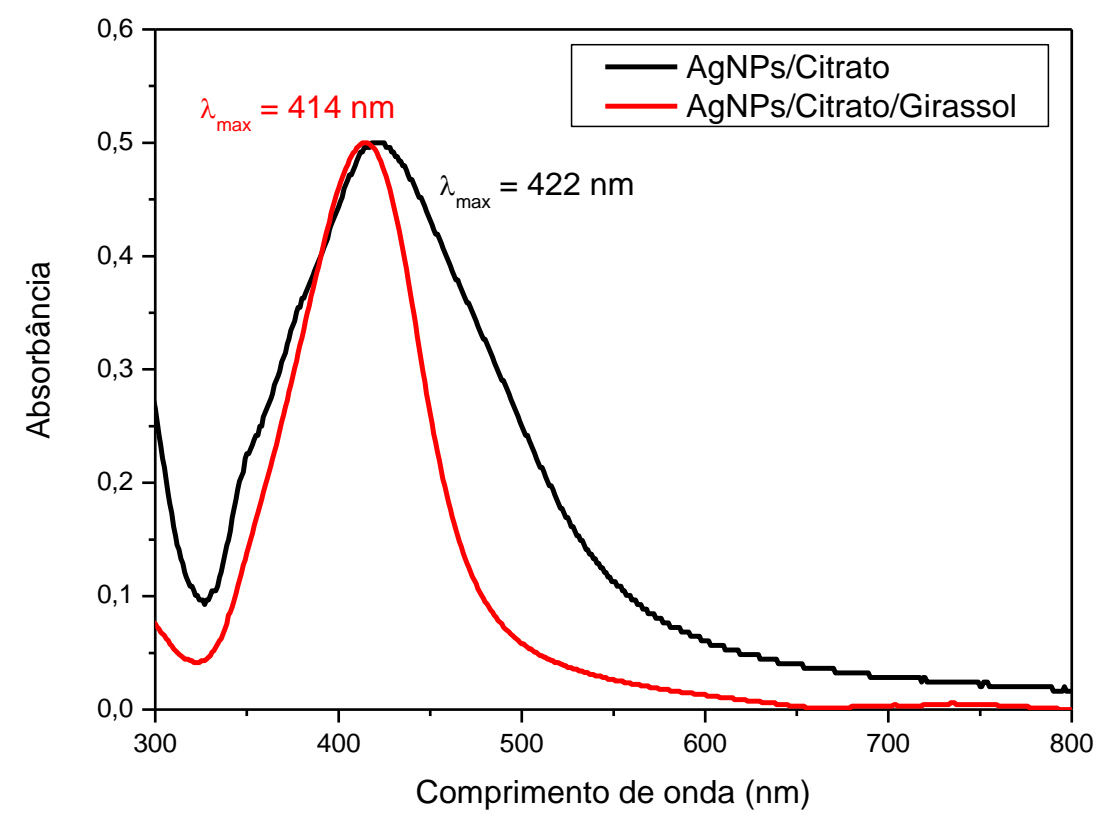

Fonte: Autores.

Na Figura 3.1 podemos observar o tamanho médio apresentado pelas nanopartículas ficou na ordem de $414 \mathrm{~nm}$ a 422 $\mathrm{nm}$ de comprimento da onda no maior volume da amostra, um pequeno volume das nanopartículas de prata apresentou uma faixa de tamanho que variou de $0,1 \mathrm{~nm}$ a $0,3 \mathrm{~nm}$ de absorbância.

\subsection{Avaliação da atividade antimicrobiana das nanopartículas}

A nanopartícula de prata é a nanoestrutura mais utilizada com o propósito de ação antimicrobiana dentre as nonopartículas projetadas devido a sua forte toxicidade para uma ampla gama de microrganismos, incluindo bactérias Grampositivas e Gram-negativas. (Liu et al., 2015; Tang; Zheng, 2018). Em adição a isso, a semente de girassol além de ser uma importante fonte de nutrientes, minerais e vitaminas, apresenta uma importante ação antimicrobiana, onde já foi demonstrando ação inibitória variada do extrato da semente de Heliantus annus contra as espécies bactericidas e fungicas de Staphylococcus aureus, Bacillus subtilis, Vibrio cholera, Aspergillus fumigates e Candida albicans (Subashini; Rakshitha, 2012).

A medida do diâmetro dos halos de inibição (média das e repetições) revelou que a ação da nanopartícula de prata associada ao substrato de girassol foi de $16 \mathrm{~mm}$ para $S$. aureus (Figura 4) e de $12 \mathrm{~mm}$ e $10 \mathrm{~mm}$ para E. coli (Figura 5) e $P$. aeruginosa (Figura 6) respectivamente, demonstrando que a ação antibacteriana desta substância é maior contra bactérias gram-positivas (S. aureus) do que para gram-negativas (E. coli e P. aeruginosa). 
Research, Society and Development, v. 10, n. 6, e11710615533. 2021

(CC BY 4.0) | ISSN 2525-3409 | DOI: http://dx.doi.org/10.33448/rsd-v10i6.15533

Figura 4: Teste de difusão em discos contendo nanopartícula de prata associada ao substrato de girassol (Ag + girassol) contra Staphylococcus aureus.

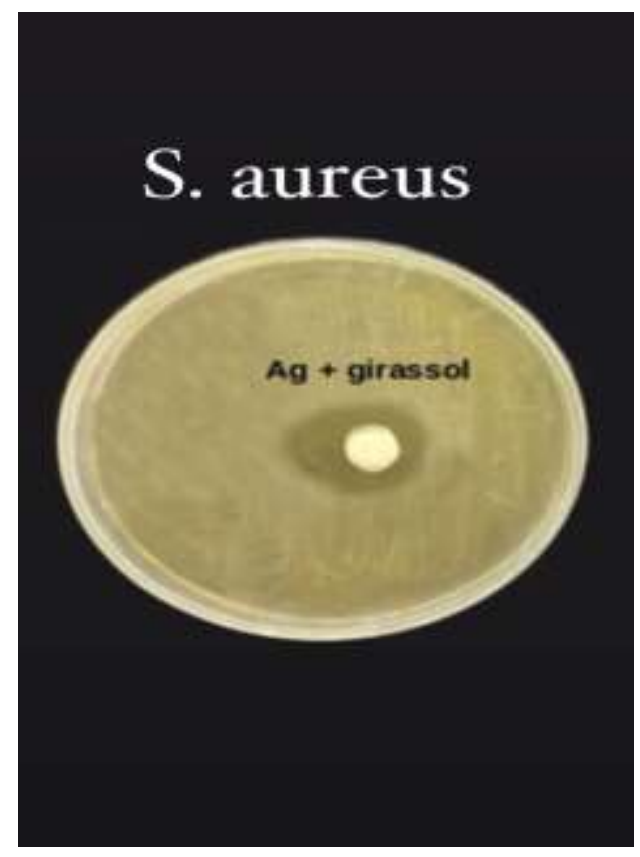

Fonte: Autores.

Figura 5: Teste de difusão em discos contendo nanopartícula de prata associada ao substrato de girassol (Ag + girassol) contra Escherichia coli.

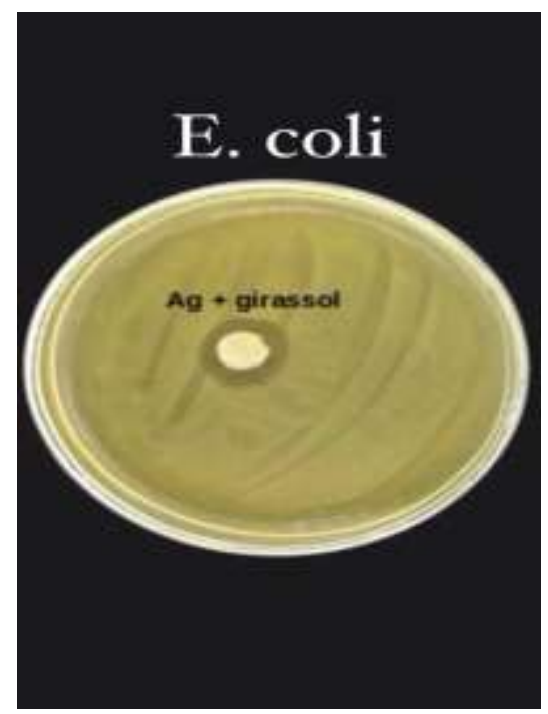

Fonte: Autores. 
Figura 6: Teste de difusão em discos contendo nanopartícula de prata associada ao substrato de girassol ( $\mathrm{Ag}+$ girassol) contra Pseudomonas aeruginosa.

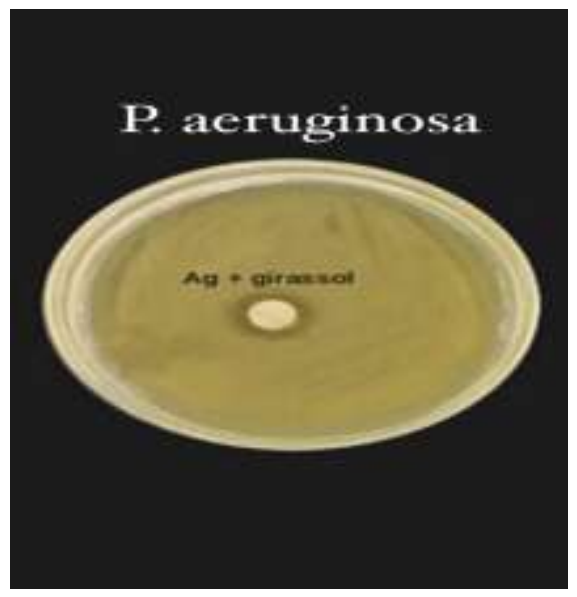

Fonte: Autores.

No ensaio de suscetibilidade por meio de disco difusão em meio sólido, observou-se a formação de halos de inibição do crescimento microbiano em todas as placas onde foram adicionados os discos contento a solução de AgNP-Ha, exceto nas amostras com Candida albicans (Figura 7), onde em nenhuma das amostras das triplicatas houve formação de halos inibitórios.

Figura 7: Teste de difusão em discos contendo nanopartícula de prata associada ao substrato de girassol (Ag + girassol) contra Candida albicans.

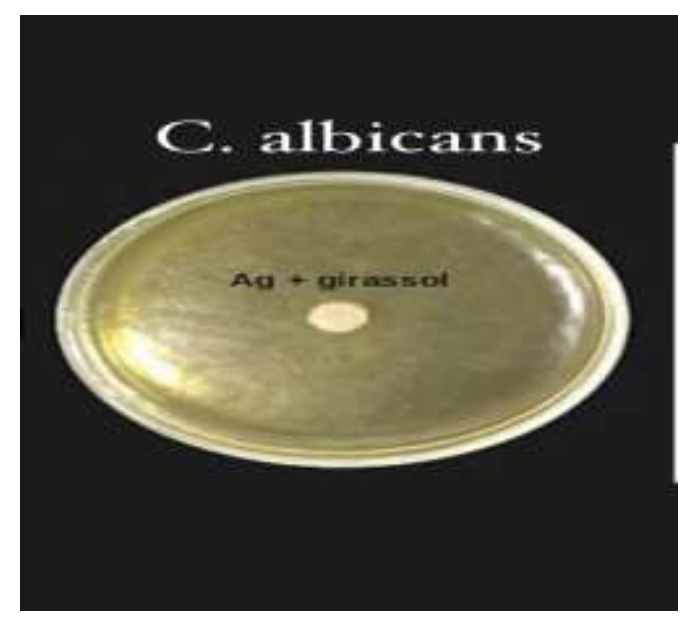

Fonte: Autores.

Em um estudo similar foi avaliada a atividade antimicrobiana de nanopartículas poliméricas à base de poli- $N$ isopropilacrilamida encapsulando nanopartículas de prata. Em concordância com o presente trabalho, o sistema de nanopartículas também apresentou efeitos contra E.coli e S. areus. Diferentemente da nanopartícula de prata estabilizada com girassol, foi relatado um maior efeito antimicrobiano contra $E$. coli do que $S$. aureus, fato que foi atribuído à diferença estrutural nas paredes das células bacterianas (Qasim et al., 2018). Semelhante à ação antibacteriana apresentada por 
nanopartículas de prata revestidas com glutationa, onde o efeito foi mais intenso em gram-negativas que em bactérias grampositivas (Taglietti et al., 2012).

As discordâncias entre os estudos podem ser atribuídas aos diferentes mecanismos de ação antimicrobiana que a nanopartícula de prata apresenta como: fixar-se na parede celular e na membrana, ocasionar danos de biomoléculas e estruturas intracelulares e promover estresse oxidativo induzido por íons de prata. Tais mecanismos podem agir de forma isolada como simultaneamente nas ações antibacterianas (Prabhu; Poulose, 2012).

Somado a isso, a composição do produto natural utilizado para estabilizar a nanopartícula influencia diretamente na atividade antimicrobiana. Devido à presença de compostos no extrato da semente de Helianthus annuus como flavonóides, alcalóides, saponinas e taninos que comprovadamente inativam as adesões microbianas, enzimas e proteínas de transporte do envelope celular (Tang et al., 2014).

\section{Conclusão}

Diante dos resultados obtidos, através da síntese verde foram desenvolvidas e estabilizadas nanopartículas de prata em extrato de girassol, tornando-se claro a eficiência das NPs ao serem sintetizadas utilizando o extrato das sementes de $H A$ como estabilizante, com características NPs com forma esférica, dimensão em torno de 20nm e coloração amarelada, comprovando ação antimicrobiana nos testes de placas realizadas com as bactérias gram-positivas e gram-negativas.

As soluções obtidas foram caracterizadas pela técnica de UV-Vis e pelo aspecto visual em que a síntese de nanopartículas de prata utilizando o extrato das sementes de Helianthus annuus promoveu uma abordagem mais amigável ao meio ambiente, simples, eficiente e com baixo custo para a obtenção de nanopartículas se tornando um excelente produto com potencial antimicrobiano para ser comercializado além de servir como subsidio para pesquisas posteriores.

\section{Conflito de Interesses}

Os autores declaram que não houve conflito de interesses.

\section{Agradecimentos}

Agradecemos imensamente aos laboratórios do Centro Universitário-UNIFACID, ao Laboratório de química do Instituto Federal do Piauí- IFPI e o laboratório de química da Universidade Federal do Piauí- UFPI.

\section{Referências}

Al-Shabib, N. A, Husain, F. M, Nadeem, M, Khan, M. S, Al-Qurainy, F., Alyousef, A. A., Arshad, M., Khan, A., Khan, J. M., Alam, P., Albalawi, T \& Shahzad. (2020). Bio-inspired facile fabrication of silver nanoparticles from in vitro grown shoots of Tamarix nilotica: explication of its potential in impeding growth and biofilms of Listeria monocytogenes and assessment of wound healing ability. RSC Advances, 10(50), 30139-30149.

Atiyeh, B. S., Costagliola, M., \& Hayek, S. (2007). Effect of silver on burn wound infection control and healing: review of the literature. Burns, 33(2): 13948 .

Bauer, A. W., Kirby, W. M., Sherris, J. C., \& Turck, M. (1966). Antibiotic susceptibility testing by a standardized single disk method. American Journal of Clinical Pathology, 45, 493-496.

Brinch, A., Hansen, S. F., Hartmann, N. B, Baun, A. (2016). EU regulation of nanobiocides: challenges in implementing the biocidal product regulation (BPR). Nanomaterials, 6(2), 33

CLSI. Clinical and Laboratory Standards Institute. (2009). Performance standards for antimicrobial disk susceptibility tests; approved standard-tenth edition M02-A10, 29(1).

Gil, A. C. (2012). Como elaborar projetos de pesquisa. (5a ed.), Atlas.

Guo, S, Ge, Y \& Jom, K. (2017). A review of phytochemistry, metabolite changes, and medicinal uses of the common sunflower seed and sprouts (Helianthus annuus L.). Chemistry Central Journal, 11(1), 1-10. 
Hong, H. R, Kim, J. \& Park, C. H. (2018). Facile fabrication of multifunctional fabrics: use of copper and silver nanoparticles for antibacterial, superhydrophobic, conductive fabrics. RSC advances, 8(73), 41782-41794.

Ibrahim, T. A, Ajongbolo, K. F., \& Aladekoyi, G. (2014). Phytochemical screening and antimicrobial activity of crude extracts of Basella albaand Helianthus annuuson selected food pathogens. Journal of Microbiology and Biotechnology, 3(2), 27-31.

Khan, I., Saeed, K., \& Khan, I. (2017). Nanoparticles: Properties, applications and toxicities. Arabian Journal of Chemistry, $12(7), 908-931$.

Kim, T. H., Kim, M., Park, H. S., Shin, S. U., Gong, M. S. \& Kim, H. W. (2012). Size-dependent cellular toxicity of silver nanoparticles. Journal of biomedical materials research Part A, 100(4), 1033-1043.

Lemire, J. A., Harrison, J. J. \& Turner, R. J. (2013). Antimicrobial activity of metals: mechanisms, molecular targets and applications. Nature Reviews Microbiology, 11(6), 371-384.

Liu, Z., Yan, J., Miao, Y., Huang, Y. \& Liu, T. (2015). Catalytic and antibacterial activities of green-synthesized silver nanoparticles on electrospun polystyrene nanofiber membranes using tea polyphenols. Composites Part B: Engineering, 79(15), 217-223.

Lucky, S. S., Soo, K. C. \& Zhang, Y. (2015). Nanoparticles in photodynamic therapy. Chemical reviews, 115(4), 1990-2042.

Oliveira, N. M. S., Resende, M. R., Morales, D. A., Umbuzeiro, G. R. \& Boriollo, M. F. G. (2016). In vitro mutagenicity assay (Ames test) and phytochemical characterization of seeds oil of Helianthus/ annuus Linn (sunflower). Toxicology Reports, 3, 733-739.

Park, K., Seo, D. \& Lee, J. (2008). Conductivity of silver paste prepared from nanoparticles. Colloids and Surfaces A: Physicochemical and Engineering Aspects, 313, 351-354.

Pinto, C. P., Rodrigues, V. D., Pinto, F. P., Pinto, R. P, Uetanabaro, A. P. T., Pinheiro, C. S. R., Gadea, S. F. M., Silva, T. R. S. \& Lucchese, A.M. (2013). Antimicrobial activity of Lippia species from the Brazilian semiarid region tradionally used as antiseptic and anti-infective agents. Evidence-Based Complementary and Alternative Medicine, 2013, 1-5.

Prabhu, S. \& Poulose, E. K. (2012). Silver nanoparticles: mechanism of antimicrobial action, synthesis, medical applications, and toxicity effects. International nano letters, 2(1), 1-10.

Qasim, M., Udomluck, N., Chang, J., Park, H. \& Kim, K. (2018). Antimicrobial activity of silver nanoparticles encapsulated in poly-N-isopropylacrylamidebased polymeric nanoparticles. International journal of nanomedicine, 13, 235.

Qiao, Z., Han, L., Liu, X., Dai, H., Liu, C., Yan, M., Li, W., Han, W., Li, X., Huang, S. \& Gao, B. (2021). Extraction, Radical Scavenging Activities, and Chemical Composition Identification of Flavonoids from Sunflower (Helianthus annuus L.) Receptacles. Molecules, $26(2), 403$.

Ravindra, S., Mohan, Y. M., Reddy, N. N. \& Raju, K. M. (2010). Fabrication of antibacterial cotton fibres loaded with silver nanoparticles via "Green Approach". Colloids and Surfaces A: Physicochemical and Engineering Aspects, 367(1-3), 31-40.

Subashini, R. \& Rakshitha, S. U. (2012). Phytochemical screening, antimicrobial activity and in vitro antioxidant investigation of methanolic extract of seeds from Helianthus annuus L. Chemical science review and letters, 1(1), 30-34.

Swietnicki, W. (2018). Recent advances in antibacterial drug development. International Journal of Recent Scientific Research, 9, 26501-26505.

Taglietti, A., Fernandez, Y. A. D., Amato, E., Cucca, L., Dacarro, G., Grisoli, P., Necchi, V., Pallavicini, P., Pasotti, L. \& Patrini, M. (2012). Antibacterial activity of glutathione-coated silver nanoparticles against gram positive and gram negative bacteria. Langmuir, 28(21), 8140-8148

Tang, D., Dong, Y., Ren, H., Li, L. \& He, C. (2014). A review of phytochemistry, metabolite changes, and medicinal uses of the common food mung bean and its sprouts (Vigna radiata). Chemistry Central Journal, 8(1), 1-9.

Tang, S. \& Zheng, J. (2018). Antibacterial activity of silver nanoparticles: structural effects. Advanced healthcare materials, 7(13), 1701503.

Thierry, B. (2009). Drug nanocarriers and functional nanoparticles: applications in cancer therapy. Current drug delivery, 6(4), 391-403. 